\title{
NO\$\$O DINHEIRO: UM JOGO SÉRIO PARA INTRODUÇÃO À EDUCAÇÃO FINANCEIRA
}

\author{
No\$\$o Dinheiro: A Serious Game to Introducing the Financial Education
}

\author{
Gustavo Guterres Leite* \\ Infância Bônes de Freitas** \\ Silvia de Castro Bertagnolli ${ }^{* * *}$ \\ Márcia Amaral Correa de Moraes ${ }^{* * * *}$
}

\begin{abstract}
Resumo: Este artigo apresenta o aplicativo "No\$\$o Dinheiro", que tem como objetivo incentivar a prática da educação financeira no ensino fundamental, por meio de um jogo sério que emprega técnicas de gamificação para fomentar o engajamento e desenvolvimento de raciocínio lógico dos estudantes. O aplicativo está organizado em duas partes: uma destinada aos estudantes, na qual realizam atividades lúdicas para compreender o sistema monetário brasileiro, simulando situações de compra e cálculos matemáticos com a nossa moeda - o Real; e a outra para os docentes, onde é possível gerenciar e fazer o acompanhamento individual da aprendizagem das turmas/estudantes. Para o desenvolvimento do estudo foi realizada pesquisa bibliográfica e pesquisa-ação, sendo que esta última foi conduzida com 18 estudantes de nível fundamental. $\mathrm{O}$ aplicativo foi avaliado de modo a delinear um perfil etário dos alunos e suas experiências prévias com jogos, bem como a usabilidade e a experiência ao interagir com o aplicativo aqui descrito. Como resultado principal pode-se apontar que o jogo contribuiu para a aprendizagem dos conteúdos da disciplina em que ele foi aplicado, conforme apontam os estudantes participantes, pois eles conseguiram identificar os elementos do sistema monetário brasileiro e realizar algumas das operações básicas da matemática. Espera-se que com aplicativo seja possível difundir e fortalecer o conhecimento do sistema monetário brasileiro entre as crianças do ensino fundamental, demonstrando a importância dos conceitos da matemática em seu cotidiano.
\end{abstract}

Palavras-chave: Educação Financeira. Sistema Monetário Brasileiro. Jogos Sérios.

\footnotetext{
* Graduado no Curso Superior de Tecnologia em Sistemas para Internet.Instituto Federal de Educação, Ciência e Tecnologia do Rio Grande do Sul - Campus Porto Alegre - RS / Brasil. E-mail: gustavo.jog@ hotmail.com.

** Mestranda em Informática na Educação - Mestrado Profissional em Informática na Educação. Instituto Federal de Educação, Ciência e Tecnologia do Rio Grande do Sul - Campus Porto Alegre - RS / Brasil. E-mail: infanciabones@gmail.com. Orcid: https://orcid.org/0000-0003-2595-9691.

**** Doutora em Computação pela Universidade Federal do Rio Grande do Sul (2004). Professora Orientadora Mestrado Profissional em Informática na Educação. Instituto Federal de Educação, Ciência e Tecnologia do Rio Grande do Sul - Campus Porto Alegre - RS / Brasil. E-mail: silvia.bertagnolli@poa.ifrs.edu.br. Orcid: https://orcid.org/0000-0001-7495-6636.
}

***** Doutora em Educação. Professora do Mestrado Profissional em Informática na Educação do

Instituto Federal de Educação, Ciência e Tecnologia do Rio Grande do Sul - Campus Porto Alegre - RS / Brasil. E-mail: marcia.correa@sertao.ifrs.edu.br. Orcid: https://orcid.org/0000-0002-6676-3698. 


\begin{abstract}
This article presents the application "No\$\$o Dinheiro", which aims to encourage the practice of financial education in elementary school, through a serious game that uses gamification techniques to foster the engagement and development of students' logical reasoning. We organize the application into two parts: one for students, in which they carry out recreational activities to understand the Brazilian monetary system, simulating buying situations and mathematical calculations with our currency - the Real; and the other part for teachers, in which it is possible to manage and monitor the individual learning of the classes or students. For the development of the study, bibliographic and action research were carried out, the latter being conducted with 18 students of fundamental level. The application was evaluated in order to delineate an age profile of students and their previous experiences with games, as well as usability and experience to interact with the application described herein. We pointed out as the main result that the game contributed to the learning of the contents of the discipline in which it was applied, as the participating students point out, because they were able to identify the elements of the Brazilian monetary system and perform some of the mathematics basic operations. It is hoped that with the application it will be possible to spread and strengthen the knowledge of the Brazilian monetary system among elementary school children, demonstrating the importance of the concepts of mathematics in their daily lives.
\end{abstract}

Keywords: Financial Education. Brazilian Monetary System. Serious Game.

\title{
1 Introdução
}

Segundo dados do Programa Internacional de Avaliação de Estudantes (PISA), coordenado pela Organização para Cooperação e Desenvolvimento Econômico (OCDE), mais de dois terços dos estudantes brasileiros $(70,25 \%)$ estão abaixo do nível básico de proficiência em Matemática, 56,6\% em Ciências e 50,9\% em Literatura (MORENO, 2016). No ranking geral, o país ficou na $65^{\mathrm{a}}$ posição, em um universo de setenta países participantes (RIBEIRO; SANTOS, 2016). Estes resultados evidenciam a dificuldade do brasileiro em lidar com lógica e números, o que por consequência afeta as mais diferentes áreas de sua vida, inclusive na esfera financeira. A falta de conhecimento básico sobre o sistema monetário do país pode resultar em pessoas com dificuldades para obter crédito ou selecionar as melhores taxas de juros e prazos (ENEF, 2010), o que indica uma tendência ao endividamento.

Frente a este cenário nada favorável, o governo federal, por meio de iniciativas como a Estratégia Nacional de Educação Financeira (ENEF) (ENEF, 2010), busca incentivar o ensino da educação financeira nas escolas. Nesse sentido, foi aprovado o projeto de Lei N. ${ }^{\circ}$ 7.318/2017, que inclui a disciplina "Educação Financeira" na matriz curricular nacional, no ensino fundamental e médio (BRASIL, 2017). Além disso, no mesmo ano, foi homologada a Base Nacional Comum Curricular (BNCC), que apresenta as diretrizes para a educação básica (MEC, 2017). Essa regulamentação estabelece várias orientações sobre o uso da matemática, em especial “... o estudo de conceitos básicos de economia e finanças, visando à educação financeira dos alunos" (MEC, 2017, p. 269). Para isso, é necessário que o estudante se aproprie do sistema monetário brasileiro, pelo do reconhecimento das cédulas e moedas existentes, como define a EF01MA19 ${ }^{1}$, habilidade prevista na BNCC.

\footnotetext{
${ }^{1}$ Observa-se que a BNCC (MEC, 2017, p. 26) identifica através de um código alfanumérico as habilidades e objetivos de aprendizagem e desenvolvimento, a sua regra de formação é detalhada no referido documento.
} 
Considerando o contexto previamente exposto, surge o problema de pesquisa: Como apresentar de forma lúdica os elementos que compõem o sistema monetário brasileiro para estudantes do ensino fundamental, seguindo os objetivos de aprendizagem estabelecidos na BNCC? Assim, foi desenvolvido e avaliado o aplicativo No $\$$ o Dinheiro, que tem como público-alvo alunos dos anos iniciais do ensino fundamental e visa a instruí-los sobre os conceitos básicos do sistema monetário brasileiro, de maneira lúdica e desafiadora. A sua versão atual conta com fases e níveis relacionados à identificação dos elementos do sistema monetário (moeda corrente), compra de bens e juros vinculados, porém para as versões futuras pretende-se incluir níveis que possibilitem compreender quais são os "princípios básicos de economia", utilizando-se dos conceitos vinculados à Educação Financeira (BRASIL, 2017).

Para o desenvolvimento do jogo foi utilizada a plataforma Android em conjunto com um banco de dados para armazenar os resultados das interações dos estudantes na nuvem. Com isso o docente pode analisar, em tempo real, as respostas de cada aluno. Essa organização permite ao docente identificar quais temáticas podem ser melhor exploradas em sala de aula, com base no desempenho dos estudantes no jogo. Observa-se ainda que, para viabilizar a inclusão de níveis e fases dinamicamente, foi desenvolvida uma arquitetura, na qual uma vez informada a pergunta e as suas respectivas alternativas, as atividades são geradas de forma automática, ou seja, a inclusão de novas fases e níveis no jogo ocorre sem a necessidade de alteração no código fonte do aplicativo.

$\mathrm{O}$ artigo prossegue apresentando alguns pressupostos teóricos que embasaram o desenvolvimento do jogo nas seções 2,3 e 4 . A seção 5 descreve alguns procedimentos metodológicos que guiaram a condução da presente pesquisa. A seção 6 detalha alguns aspectos da concepção e do desenvolvimento do jogo No\$o Dinheiro. A seção 7 traz alguns dos resultados obtidos com a aplicação do jogo em uma Escola Municipal, bem como algumas reflexões sobre estes. Por fim, na seção 8, apresentam-se as conclusões obtidas com este trabalho.

\section{Gamificação no contexto educacional}

Existem diversos fatores que motivam o uso de jogos na educação, mas, segundo Macedo, Petty e Passos (2005), três dimensões são as mais relevantes para o seu uso no ambiente escolar: a dimensão lúdica, que tem relação com o prazer que os estudantes possuem em jogar e aprender usando recursos pedagógicos não tradicionais, o desafio e a surpresa proporcionados pelo jogo são fatores de engajamento; a dimensão simbólica traz para o jogo tarefas e atividades que são "motivadas" e "enriquecidos de histórias, músicas, imagens, imitações" (p. 20); a dimensão construtiva, que tem como foco oferecer liberdade para o fazer e para errar, mas sempre com a intencionalidade do aprender.

Aliada à teoria dos jogos na educação, nos últimos anos a gamificação tem despertado o interesse de docentes e pesquisadores. O termo gamificação, do inglês "gamification", denota a ação de usar os fundamentos de jogos em atividades que não são jogos, em especial as que estão vinculadas à educação (GIRAFFA;LIMA;MARTINS, 2018). Kapp (2012, p. 33) define a gamificação como sendo "o uso de mecânicas, estética e pensamentos dos games para envolver pessoas, motivar a ação, promover a aprendizagem e resolver problemas". Segundo Kim et al (2018), a gamificação não é somente para aprender brincando e se divertindo. Com ela é possível aumentar o envolvimento e o engajamento dos estudantes na sua aprendizagem, promover as habilidades de colaboração e cooperação e favorecer a mudança comportamental. $\mathrm{O}$ seu uso na área educacional pode trazer inúmeros benefícios, entre os quais o 
desenvolvimento do raciocínio, conhecimento prático, interação e reflexão, pois os alunos estão mais motivados e engajados nas atividades propostas (GIRAFFA;LIMA;MARTINS, 2018).

Por fundamentos de jogos, entende-se características como a definição de regras e objetivos claros, para que se possa alcançar determinada conquista. Com o intuito de manter o jogador motivado, os fundamentos da gamificação incluem ainda sistemas de feedback, competição, pontuação e emblemas/troféus, para quando os objetivos são cumpridos com êxito (KIM et al. 2018; ZICHERMANN; LINDER, 2013). Neto (2015) estabelece três categorias de elementos de jogos para conceber uma gamificação adequada: dinâmicas, mecânicas e componentes.

As dinâmicas são compostas pelos seguintes itens (NETO, 2015): narrativa - que descreve a história a ser percorrida; emoções - a capacidade de despertar emoções humanas, como ansiedade, solidariedade, entre outras; restrições - proibições ou restrições para que o jogador possa percorrer alguns caminhos dentro do jogo; progresso - indicadores que mostram como o jogador está evoluindo no jogo; relacionamentos - como os jogadores irão interagir uns com os outros.

As mecânicas são estabelecidas utilizando-se os elementos a seguir (NETO, 2015; ALVES, 2014): desafios - as tarefas que o jogador deve solucionar; competição - mecânica que estabelece como o jogador ganha ou perde, sendo que nem todos os jogos usam competição; cooperação - como os jogadores podem ajudar os outros jogadores; feedback - indicações se o jogador está ou não no caminho certo; recompensa - é dado ao jogador algum benefício que é resultante de seus resultados no jogo; além de outros elementos que são definidos por Alves (2014).

Alguns dos principais componentes que devem fazer parte de um sistema gamificado compreendem: desafios com objetivos claros; conquistas, que dão a sensação de progresso ao jogador; medalhas, que são representações visuais das conquistas; pontuação, que mostram o progresso do jogador através de alguma representação numérica; níveis, que são as etapas no progresso do jogador; ranking ou placar, que permite ao jogador analisar o seu desempenho se comparado aos demais jogadores (ALVES, 2014; NETO, 2015).

\section{Jogos Sérios: contextualização e definições}

Nos últimos tempos, várias pesquisas têm demonstrado a importância do uso de jogos na área educacional (PRENSKY, 2002; 2012; PETRI; WANGENHEIM; BORGATTO, 2019; MORAIS; FALCÃO, 2019). Um game com o propósito apenas para o entretenimento tem características diferentes daqueles que são elaborados e desenvolvidos para uso em ambiente educacional. Os jogos sérios são "utilizados com propósito de ensino-aprendizagem ou treinamento de pessoas, e não apenas para diversão" (ROCHA et al., 2016, p. 109).

Para Rocha (2014), os jogos sérios são aqueles que possuem metas desafiadoras voltadas para a construção de conhecimento sobre os mais variados temas. Desta forma, esse tipo de jogo concentra-se em objetivos específicos de aprendizagem e, para obter um melhor resultado, utiliza-se de elementos como competição, recompensas, troféus, entre outros componentes, de forma similar à gamificação. Para Eid, Laamarti e Saddik (2014), um jogo sério é baseado em três componentes: experiência, entretenimento e multimídia, pois ele tem o potencial de melhorar a experiência do usuário por meio de interação multimodal, através de mídias diferentes, que podem ser uma combinação de textos, gráficos, animações, áudio, diversos recursos multimídia; além de possibilitar o entretenimento e viabilizar o aperfeiçoamento de algum conhecimento ou habilidade do jogador. 
Ainda segundo Eid, Laamarti e Saddik (2014), existe uma série de critérios que podem identificar o potencial de um jogo sério (Figura 1): a área de aplicação (do inglês: application area), ou seja, em qual domínio ele será utilizado; a atividade (do inglês: activity), ou seja, o tipo de ação desempenhada pelo jogador em resposta ao "input" do jogo, se ela se concentra mais em esforço físico, fisiológico ou mental; a modalidade (do inglês: modality), que compreende o canal sobre o qual a informação é transmitida da máquina para jogador; o estilo de interação (do inglês: interaction style), que diz respeito a forma com que o usuário irá interagir com ele; e, por fim, o ambiente (do inglês: environment), que define qual é o tipo de tecnologia utilizado para o espaço gráfico do jogo, ou seja, por meio de presença social, usando ambiente virtual, recursos 2D/3D, dispositivos móveis ou recursos online.

Figura 1 - Taxonomia Para Jogos Sérios
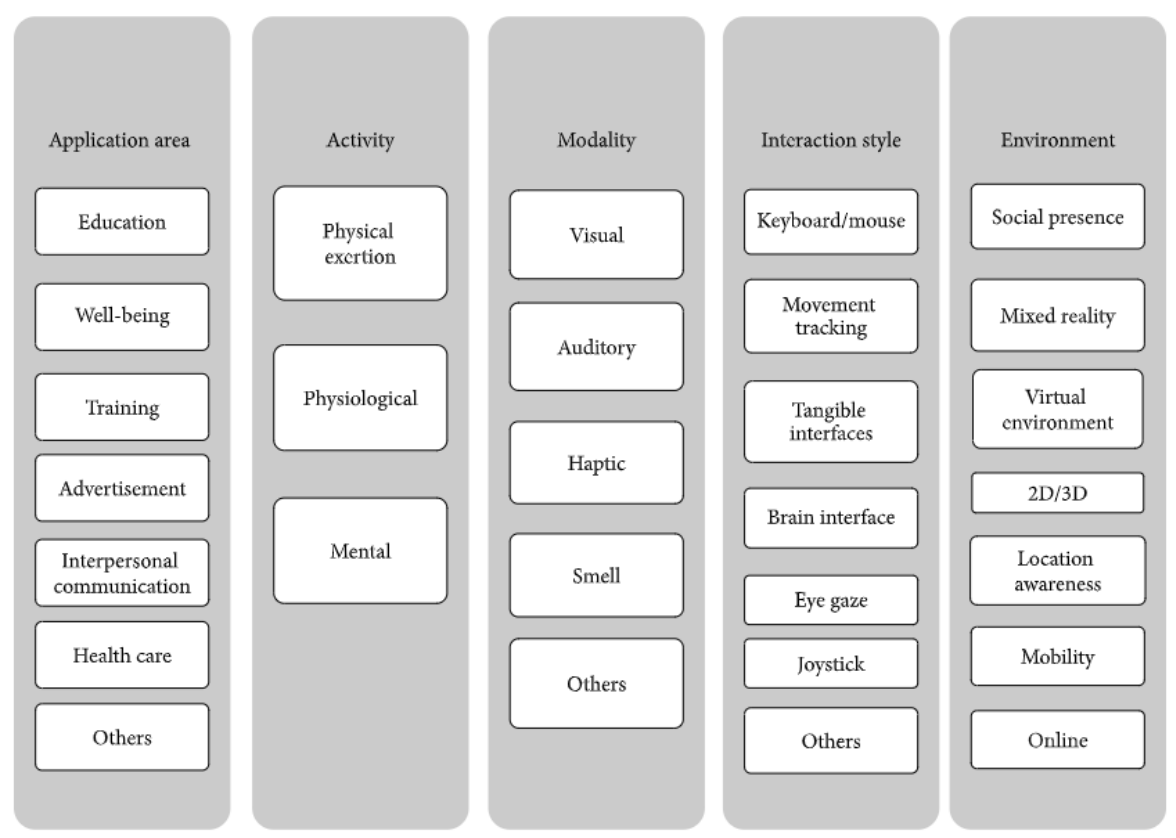

Fonte: Eid; Laamarti; Saddik (2014).

No contexto deste trabalho, o jogo desenvolvido se encaixa na área de educação e atividade mental. A modalidade de transmissão da informação entre usuário e aplicativo é a visual, e o tipo de interação é "touchscreen". Por fim, a tecnologia 2D foi selecionada para a ambientação gráfica do game No\$o Dinheiro.

\section{Educação Financeira: histórico e percepções}

A OCDE em 2005, publicou um conjunto de recomendações sobre os princípios e as boas práticas de educação e conscientização financeira na educação básica. Neste documento consta referência ao Financial Education Project, o qual possuía o intuito de determinar o nível de educação financeira em todos os países membros da OCDE (OCDE, 2005). Porém, a OCDE recomendava, aos países que não possuíam os recursos necessários para a identificação deste nível, estabelecer uma parceria com bancos privados e públicos. Muitos foram contra essa abordagem, visto que os bancos possuem como objetivo ter lucro, e que a educação financeira tem que propiciar "não só a saúde da vida financeira pessoal, mas do mesmo modo o bem coletivo como um todo" (SILVA, 2020). 
Em 2010 é instituída no Brasil, pelo governo federal, a Estratégia Nacional de Educação Financeira (ENEF), a qual busca incentivar o ensino da educação financeira nas escolas, visando a fortalecer a cidadania. Em etapa posterior, o projeto de Lei N. ${ }^{\circ}$ 7.318/2017, foi aprovado pela Câmara dos Deputados e inclui a disciplina "Educação Financeira" na matriz curricular nacional, no ensino fundamental e médio (BRASIL, 2017). Esse projeto de lei altera a redação dos Artigos 26, 32 e 36 da Lei no 9.394, de 20 de dezembro de 1996. Os Artigos 32 e 36 determinam a necessidade de compreensão dos princípios básicos de economia por meio da Educação Financeira por parte dos estudantes. Já o Artigo 26 estabelece, entre outras coisas, que: "Os currículos do ensino fundamental e médio devem abranger, obrigatoriamente, a matéria 'Educação Financeira"”.

A BNCC (MEC, 2017) estabelece que o estudo de conceitos básicos de economia e finanças, com o intuito de propiciar a educação financeira dos alunos, deve ser abordada no ensino fundamental, dentro da unidade temática da matemática. Ela propõe como temas a serem referenciados "taxas de juros, inflação, aplicações financeiras (rentabilidade e liquidez de um investimento) e impostos", recomendando que o estes sejam articulados de forma integrada com outras áreas do conhecimento.

Porém, antes de iniciar com a educação financeira visando ao sistema econômico é essencial que o estudante reconheça os elementos do sistema monetário brasileiro e consiga realizar operações básicas usando cédulas e moedas. Alinhada a essa necessidade a BNCC destaca os itens de estudo vinculados à educação financeira, começando pela área e delimitando até chegar em uma habilidade de estudo específica. $\mathrm{Na}$ área da matemática, unidade temática "Grandezas e Medidas", os objetos de estudo são detalhados por ano do ensino fundamental: no $1^{\circ}$ ano, por exemplo, os tópicos giram em torno do reconhecimento de cédulas e moedas para que o estudante esteja apto a resolver situações simples do seu cotidiano, conforme a habilidade "EF01MA19"; no $2^{\circ}$ ano, estão previstos conteúdos que envolvam a comparação e a equivalência de valores monetários do sistema brasileiro em situações de compra, venda e troca, conforme a habilidade "EF02MA20"; e, no $3^{\circ}$ ano, estão previstos conteúdos para utilizar diferentes procedimentos de cálculo mental e escrito, resolver problemas de adição e subtração com números naturais, conforme a habilidade "EF03MA05".

Dessa forma, o presente trabalho descreve as primeiras experiências relacionadas com a elaboração e avaliação do jogo sério No\$\$o Dinheiro, considerando que no escopo as atividades foram planejadas de modo a contemplar os estudantes dos anos iniciais do ensino fundamental. A ideia é que sejam planejados fases e níveis que contemplem, gradativamente, o reconhecimento do sistema monetário brasileiro, grandezas proporcionais, cálculo de percentuais, juros simples, juros compostos, impostos, taxas e rendimentos sobre investimentos, enfim, os mais diversos conceitos relacionados com a educação financeira. Optou-se por elaborar o jogo dessa forma para que fosse possível, em um primeiro momento, avaliar se a sua estrutura atendia as necessidades dos estudantes e se os seus elementos favoreciam a aprendizagem.

\section{Percurso Metodológico}

No decorrer do desenvolvimento do presente trabalho, foi empregada a metodologia de pesquisa bibliográfica para elaboração e compreensão dos conceitos que deveriam ser explorados no aplicativo. Nessa pesquisa foi possível observar que o aplicativo deveria usar recursos de gamificação (por exemplo, desafios, feedback e progresso) (ALVES, 2014; NETO, 2015) e de jogos sérios (tem como foco o aprendiz e objetivos a aprendizagem e a avaliação) (ROCHA, et al., 2016), e que os primeiros níveis deveriam abordar questões essenciais de 
matemática básica, antes da inclusão de níveis relativos aos conteúdos de matemática financeira. Essa etapa foi essencial, pois ela possibilitou estabelecer que a estrutura do aplicativo deveria viabilizar que o conhecimento fosse evoluindo de modo progressivo, em um primeiro momento a apresentação da moeda brasileira - o Real - e das operações básicas, para posteriormente incluir a educação financeira. Os conteúdos e/ou objetos de conhecimento de matemática envolvem o emprego de conceitos abstratos por parte dos estudantes. Assim, a ideia era permitir que eles fossem explorados usando uma estratégia pedagógica diferentes da tradicional, que não contemplasse apenas a repetição de exercícios, e que estivesse relacionada com a vida cotidiana dos estudantes.

Por meio de uma pesquisa-ação, que envolveu os autores do trabalho e participantes externos, o jogo começou a ser projetado e modelado. Inicialmente foram criados protótipos de baixa fidelidade, os quais foram validados com os estudantes que utilizariam o aplicativo. Esse processo de validação segue os princípios do design de interação centrado no usuário, no qual o usuário ajuda a aprimorar o projeto da interface gráfica (ROGERS; SHARP; PREECE, 2013). Com o uso dessa abordagem, foi possível identificar qual seria a melhor fonte (tipografia) a ser usada, a posição mais adequada para os botões, a orientação que as telas do aplicativo deveriam adotar, a distribuição da informação e a representação das cédulas. Destaca-se que esse tipo de protótipo é construído em papel, usando colagens e outros materiais de baixo custo e tem o objetivo principal de verificar o comportamento e as reações do usuário como se estivesse interagindo com o game proposto.

Figura 2 - Protótipos de Baixa Fidelidade

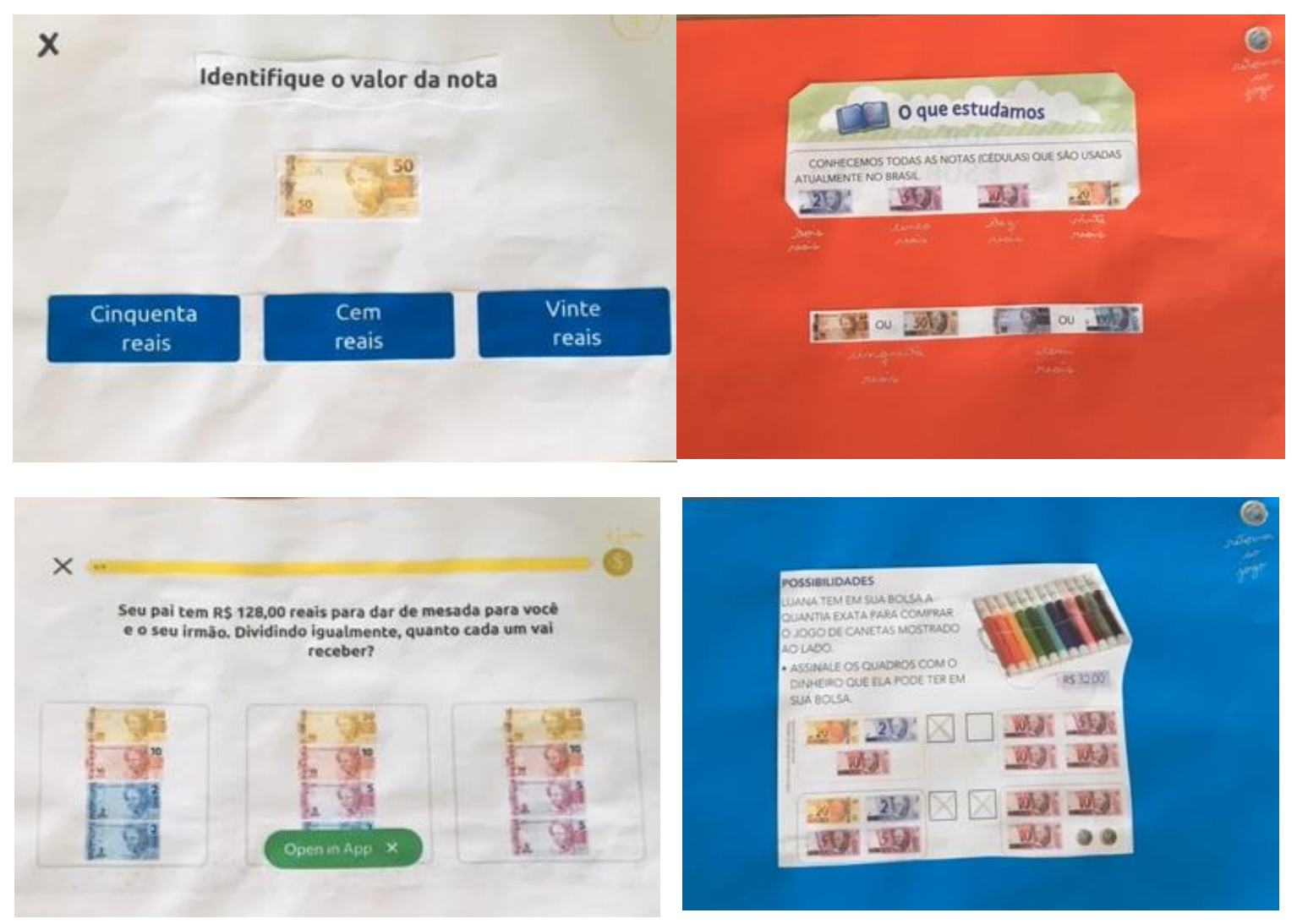

Fonte: Elaborado pelos autores, 2019. 
Ao concluir a avaliação do protótipo de baixa fidelidade, foram elaborados protótipos digitais (Figura 3) com o auxílio da ferramenta Marvel app². Após todas as dúvidas relacionadas à estrutura, e a organização das fases e níveis do jogo serem selecionadas, ele começou a ser implementado para a plataforma Android.

Figura 3 - Protótipos em Alta Fidelidade - Ferramenta Marvel App
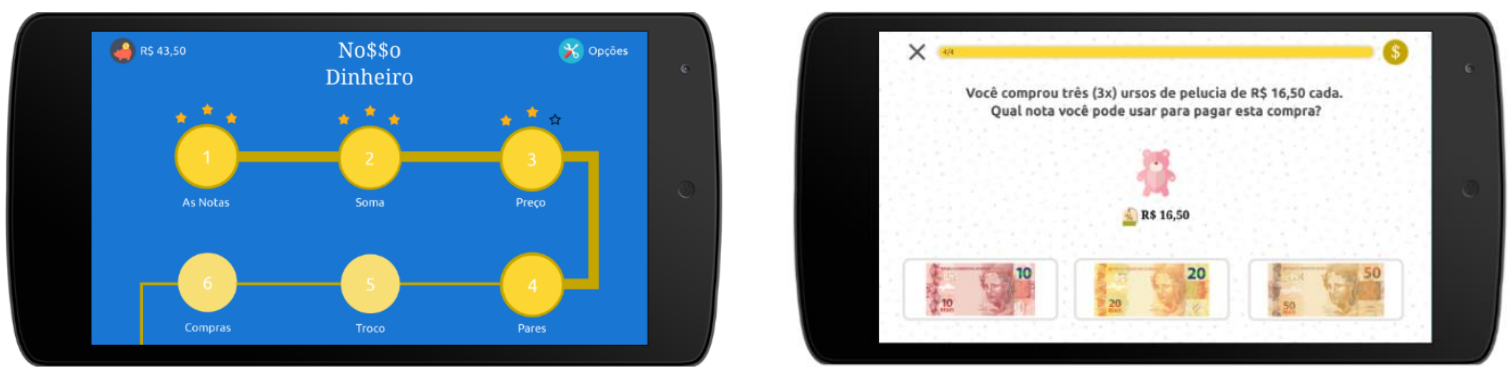

Fonte: Elaborado pelos autores, 2019.

No início do projeto pensou-se em duas alternativas para estruturar o aplicativo: um sistema gamificado ou um jogo sério. Assim, com o intuito de ajudar a esclarecer melhor a natureza do trabalho, foram realizadas algumas entrevistas com profissionais com experiência na área de informática na educação e conhecimentos prévios sobre esses conceitos. Após a apresentação do protótipo digital, os participantes deveriam analisá-lo sob a perspectiva teórica do jogo sério e sob o olhar da gamificação, para então determinar em qual categoria ele melhor se encaixava. A partir das entrevistas, os profissionais convergiram para a alegação de que o aplicativo consistia em um jogo sério, pois se trata de um tema específico (o ensino da matemática financeira para crianças). Outros aspectos mencionados que corroboram com este ponto de vista foram a clareza e simplicidade do sistema, bem como a possibilidade de controle e observação do aluno por parte do professor. Eles ainda apontaram que ele possuía alguns elementos da gamificação, como o progresso, o feedback, a recompensa e os desafios. Essa experiência foi importante para apontar a direção que o aplicativo deveria adotar e, com base em alguns comentários, percebeu-se a necessidade de defini-lo com uma arquitetura dinâmica que pudesse incorporar novos níveis e fases progressivamente.

O momento subsequente ao desenvolvimento foi uma pesquisa-ação com 18 estudantes de nível fundamental, anos iniciais de uma escola municipal do Rio Grande do Sul. O aplicativo No\$o Dinheiro foi apresentado aos estudantes usando um tablet. Após, eles foram convidados a responder um questionário que permitiu avaliar a sua qualidade. O software foi avaliado no modelo de avaliação de jogos educacionais MEEGA+ ${ }^{3}$, que compreende um modelo sistemático que permite uma avaliação da qualidade educacional sob a perspectiva dos estudantes no contexto da educação em computação (PETRI; WANGENHEIM; BORGATTO, 2018). Cabe observar que a presente pesquisa foi aprovada pela comissão de ética em pesquisa e que os participantes, bem como seus responsáveis, foram esclarecidos em relação ao objetivo da investigação e assinaram o termo de consentimento livre e esclarecido/termo de assentimento, autorizando a publicação dos dados. A seção 7 irá apresentar em detalhes os procedimentos adotados para a avaliação do jogo No\$ \$o Dinheiro.

\footnotetext{
2 Disponível em: https://marvelapp.com/

${ }^{3}$ http://www.gqs.ufsc.br/quality-evaluation/meega-plus/
} 


\section{No\$\$o Dinheiro: concepções e funcionamento}

Para o desenvolvimento do aplicativo foi utilizado o processo de design de jogos educacionais EnGAGED (BATTISTELLA, 2016) e o modelo de design instrucional ADDIE (Analysis, Design, Develop, Implement, Evaluate) (BRANCH, 2009). Inicialmente, foi estabelecida a meta instrucional, após foi delimitado o contexto de aplicação do game e o perfil dos estudantes. Ao começar a elaboração do game No\$\$o Dinheiro verificou-se que a forma mais viável de sistematizá-lo seria através de um mecanismo de Quiz, na qual cada pergunta representa uma fase. Neste cenário, cada nível consiste no agrupamento de cinco diferentes fases sobre um mesmo tema, os quais são desbloqueados conforme o progresso do usuário. Observa-se que estas fases foram definidas seguindo as unidades temáticas da matemática ("Grandezas e Medidas", com o reconhecimento de cédulas e moedas; e a comparação e a equivalência de valores monetários do sistema brasileiro em situações de compra, venda e troca) previstas na BNCC, e considerando apenas os anos iniciais do ensino fundamental.

As principais funcionalidades do aplicativo compreendem: o Login, que é usado pelo estudante e pelo professor, para que o docente possa identificar o progresso de cada estudante nos conteúdos abordados pelo aplicativo; o acesso aos resultados, que permite ao professor visualizar o andamento de cada estudante nas fases e níveis que fazem parte do jogo. $\mathrm{O}$ professor ainda tem acesso às funcionalidades de gerenciar turmas e gerenciar alunos, as quais permitem que o professor realize o cadastro das turmas e dos alunos que fazem parte dela no sistema. A principal funcionalidade é a de responder desafios que permite que o estudante jogue os níveis e fases, sendo que o aplicativo registra as respostas dadas nas interações.

Cada nível apresenta uma breve introdução acerca do tema, que pode conter a história do dinheiro, no que consiste o sistema monetário brasileiro, como usar as moedas, como fazer compras, como calcular o troco, entre outras. Foi levantada a hipótese de que a criança pode sentir-se desestimulada a continuar, caso tenha dificuldade em acertar as cinco questões para conseguir avançar de nível. Visando a evitar essas situações, foi elaborado um sistema de progressão adaptado, no qual o jogador pode avançar de nível desde que acerte pelo menos três das cinco questões. Com o intuito de manter o jogador engajado em acertar o máximo possível das questões, foi planejado um sistema de recompensa, no qual o jogador acumula pontos por cada resposta correta. Assim, o professor pode recompensar o estudante que tiver maior pontuação da forma que achar mais adequada.

Ao concluir a definição das funcionalidades foi sistematizada a identidade visual do aplicativo. Segundo Rogers, Sharp e Preece (2013), é essencial utilizar-se das cores para completar a experiência do usuário e tornar a aplicação mais intuitiva. Pensando nisso, para a prototipação das telas, o amarelo foi escolhido como cor de destaque, pois representa a sabedoria. $\mathrm{O}$ azul foi escolhido porque traduz confiança e tranquilidade. Como complemento, o branco é utilizado para completar os espaços, pois dá sensação de clareza.

Na Figura 4 é possível observar as principais telas que compõem o jogo: a tela inicial (Figura 4 (a)) contém uma lista dos níveis disponíveis para jogar; ao selecionar o nível 1 "As notas" o estudante navega para uma tela de introdução, na qual são explicados brevemente conceitos referentes ao assunto do nível em questão (Figura 4 (b)), e em seguida ele é redirecionado para a primeira das cinco fases (Figura 4 (c)). Note-se que a pontuação total do estudante é exibida na tela principal (Figura 4 (a) canto superior direito), o progresso do estudante é destacado na parte superior da fase, onde é exibido o número de questões relacionadas com a fase e quantas ainda ele deve fazer (Figura 4 (c)). 
Figura 4 - No\$\$o Dinheiro: visão do aluno

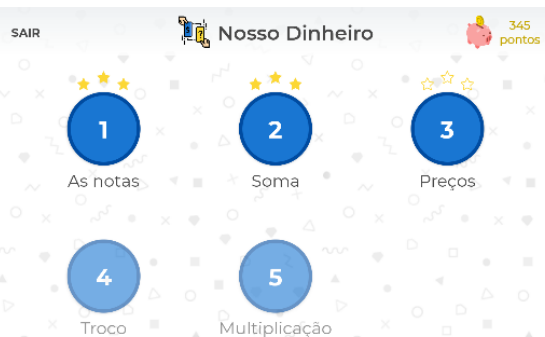

(a)

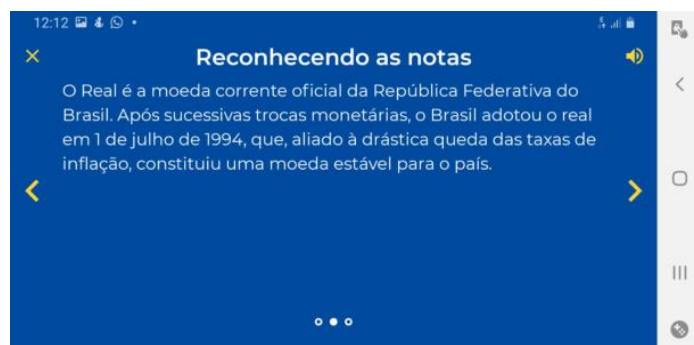

(b)

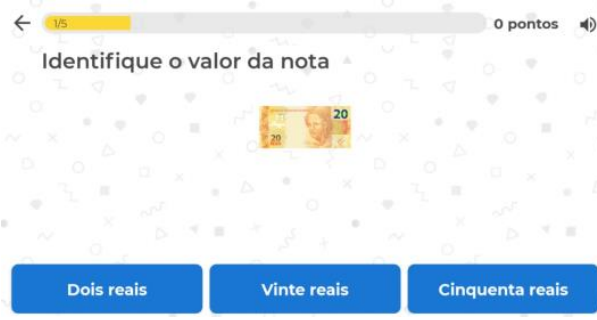

(c)

Fonte: Elaborado pelos autores, 2019.

A Figura 5 esquematiza a interface que é exibida quando o usuário é professor. Na tela inicial (Figura 5 (a)) é possível gerenciar as turmas. Caso o usuário selecione uma turma já cadastrada, é aberta a segunda tela (Figura 5 (b)), na qual é possível ver os detalhes de uma determinada turma, bem como fazer o acompanhamento do progresso do estudante durante as suas interações (Figura 5 (c)). Como o conjunto de informações que devem ser exibidas para o docente é diferente do jogo, essas são apresentadas utilizando-se a orientação vertical, pois isso facilita o acesso ao progresso dos estudantes.

Figura 5 - No\$\$o Dinheiro: visão do professor



(a)

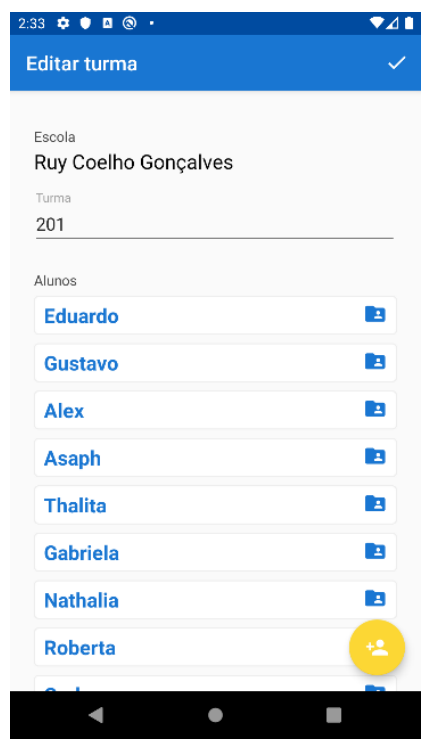

(b)

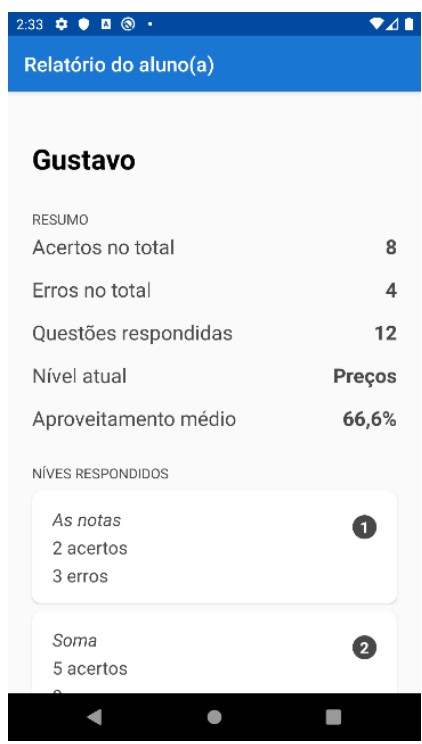

(c)

Fonte: Elaborado pelos autores, 2019. 
Durante a fase de prototipação, observou-se que os níveis possuem todos uma estrutura em comum. Todas as telas apresentam, no topo, uma barra de progresso em conjunto com dois botões auxiliares: no centro, um texto e/ou imagem sobre a questão em si, e no rodapé uma lista de " $n$ " opções a serem selecionadas como resposta.

A partir disso, foi proposta uma arquitetura dividida em três pilares, sendo que o primeiro diz respeito aos dados, na qual todas as informações pertinentes, como textos da tela, progresso do usuário e até mesmo os níveis em si, devem ter sua origem em um banco de dados. O segundo ponto diz respeito ao layout, pois todos elementos visuais devem ser constituídos de componentes menores que, quando combinados, formam a interface gráfica do sistema. $\mathrm{O}$ terceiro é responsável por montar as telas de forma dinâmica. Com essa arquitetura é possível incluir novas fases e níveis no jogo de forma dinâmica.

Essa estrutura foi elaborada de modo que o conhecimento fosse incorporado de modo progressivo no jogo, em um primeiro momento apresentação da moeda brasileira - o Real, as operações básicas, para posteriormente incluir a educação financeira. Isso porque, os conteúdos e/ou objetos de conhecimento de matemática, envolvem o emprego de conceitos abstratos por parte dos estudantes, e esses devem ser explorados usando uma estratégia pedagógica diferente da tradicional, que não fosse baseada na repetição de exercícios e que estivesse relacionada com a vida cotidiana dos estudantes.

\section{Discussões e Resultados}

Para a validação do No\$ \$o Dinheiro foi elaborado um questionário com perguntas que constam no modelo MEEGA+, o qual é um usado para "avaliar a qualidade dos jogos educacionais". Ele possibilita que os alunos avaliem o jogo sob o ponto de vista da experiência e da usabilidade do "jogador". Conforme já mencionado, o aplicativo foi avaliado por um grupo de 18 estudantes de ensino fundamental da rede pública de ensino. Os alunos encontravam-se distribuídos nas faixas etárias descritas no Quadro 1.

Quadro 1 - Faixa Etária dos Alunos Participantes da Pesquisa

\begin{tabular}{|l|l|}
\hline Faixa etária & Quantidade \\
\hline 6 anos & 1 \\
\hline 7 anos & 3 \\
\hline 8 anos & 6 \\
\hline 9 anos & 3 \\
\hline 10 anos ou mais & 5 \\
\hline
\end{tabular}

Fonte: Elaborado pelos autores, 2019.

Uma das primeiras perguntas que foi realizada dizia respeito à frequência com que os estudantes jogam, visando a delimitar o grau de contato com games e seu contato com a tecnologia através de jogos. O Gráfico 1 apresenta os resultados da frequência com que os estudantes participantes interagem com jogos digitais e não digitais. Os dados obtidos destacam um percentual bem alto de alunos que não possuem o costume de jogar usando recursos digitais e que os estudantes estão mais acostumados a atividades vinculadas a tabuleiros e cartas. Esses dados possuem relação com a faixa etária dos estudantes e o seu perfil, visto que são alunos matriculados em um Município do interior, onde os pais controlam o uso dos dispositivos eletrônicos. Cabe observar que o contato dos estudantes com jogos é realizado 
predominantemente na escola $(96 \%)$ e que estes são predominantemente de tabuleiro, pois a escola não possui muitos recursos tecnológicos como computadores e tablets.

Gráfico 1 - Gráfico de frequência de jogos digitais x jogos não-digitais

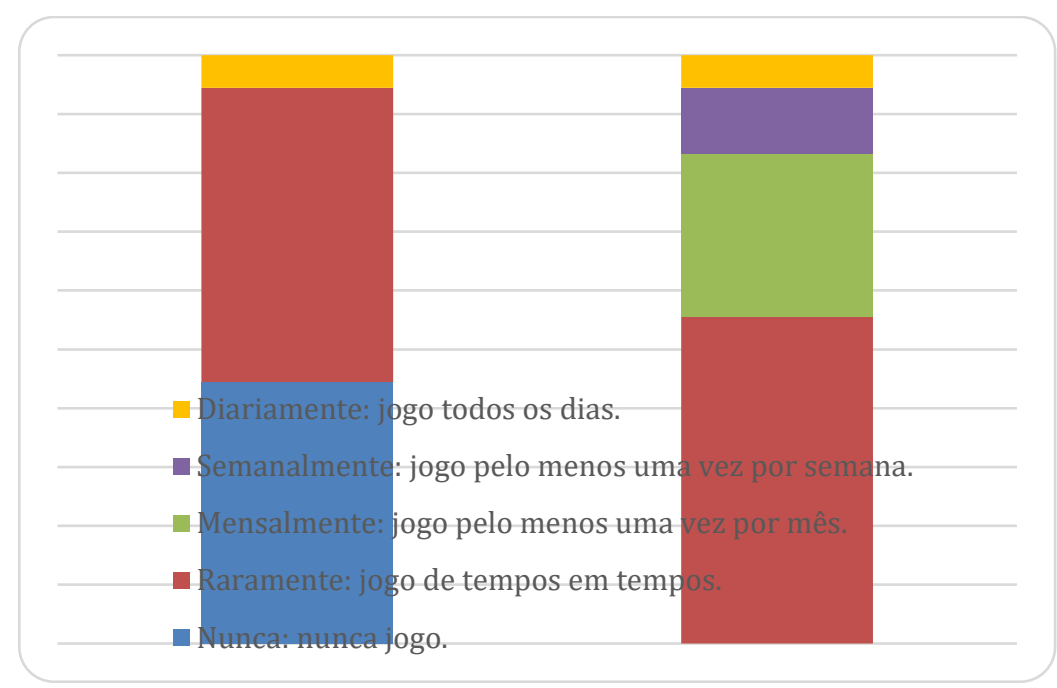

Fonte: Elaborado pelos autores, 2020.

Os estudantes participantes da pesquisa utilizaram alguns dos níveis propostos para o jogo. Os alunos relataram que acharam mais fácil os dois níveis introdutórios, que abordavam a identificação de cédulas e valores nas notas (exercícios semelhantes ao ilustrado pela Figura 4 (c)) e a soma de notas (Figura 6 (a)) para a compra de um produto. Durante a realização da atividade percebeu-se que, quando a soma de moedas envolvia centavos, os alunos ficavam com muitas dúvidas se estavam realizando a operação corretamente. Já nos demais níveis, relativos à combinação de notas para a compra de algum item, ou que envolviam somar (multiplicação) várias vezes o mesmo valor (exercícios semelhantes aos da Figura 6 (c) e (d)) os alunos apresentaram muita dificuldade, e em alguns casos usaram materiais concretos como lápis e papel para resolver os cálculos matemáticos. 
Figura 6 - No\$\$o Dinheiro: níveis e fases

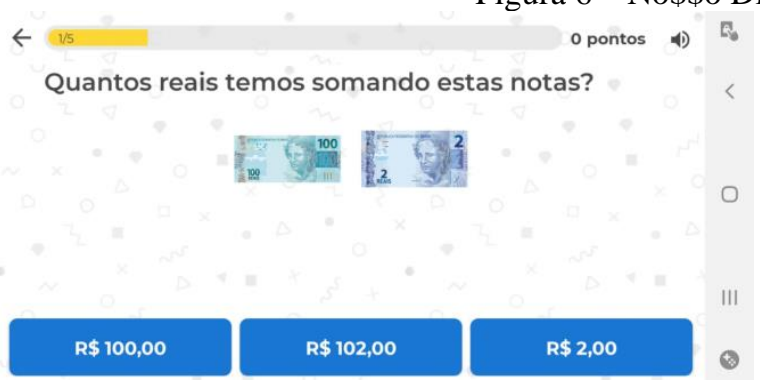

(a)

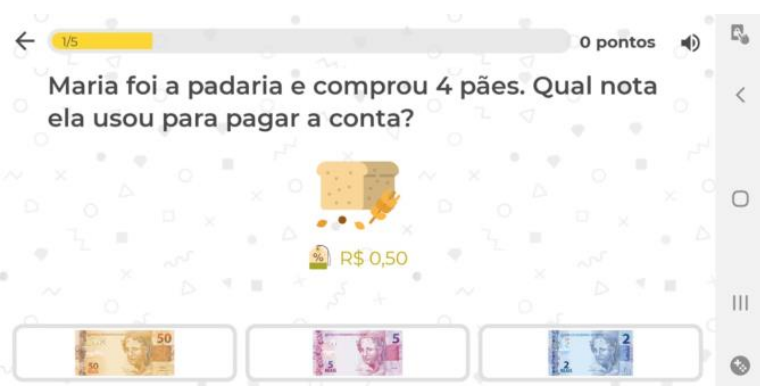

(c)

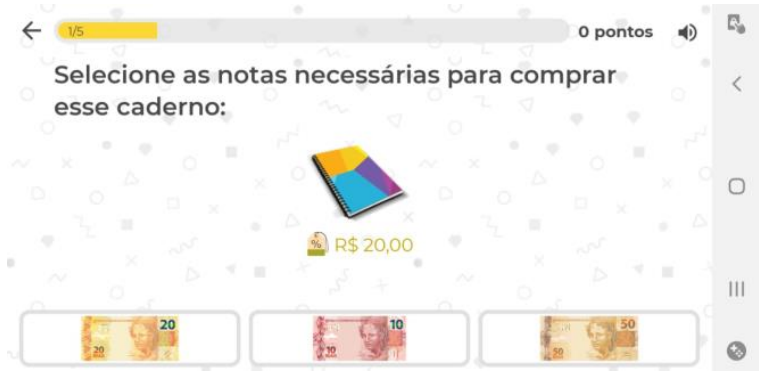

(b)



(d)

Fonte: Elaborado pelos autores, 2020.

Os alunos relataram ainda que não reconheciam algumas das notas apresentadas no jogo. A maioria já havia visto notas com valor mais baixo ( $\mathrm{R} \$ 2,00$ e $\mathrm{R} \$ 10,00)$ e moedas de diversos valores. Pode-se afirmar que os estudantes conseguiram, com relação ao sistema monetário brasileiro, reconhecer as cédulas e moedas, mas em alguns casos não conseguiram estabelecer a equivalência de valores.

Nessa primeira aplicação, a docente responsável pela turma acompanhou o uso de jogo por cada aluno, visando a identificar as dificuldades de aprendizagem e de uso do jogo. Mesmo assim, com a observação realizada foi possível identificar que alguns conteúdos deveriam ser reforçados como "Problemas envolvendo diferentes significados da adição e da subtração (juntar, acrescentar, separar, retirar)" (MEC, 2017, p. 282). Como os alunos recorreram ao uso do papel para a resolução de alguns cálculos percebeu-se a importância de fortalecer a "(EF02MA05) Construir fatos básicos da adição e subtração e utilizá-los no cálculo mental ou escrito" (MEC, 29017, p. 283). Além disso, ao constatar as dificuldades com o uso de centavos decidiu-se reforçar a multiplicação (por 2, 3, 4 e 5), bem como o que significa dobro, metade, triplo e terça parte. Isso porque, como estabelece a EF02MA07 e a EF02MA08, alunos do segundo ano do Ensino Fundamental devem, respectivamente: "Resolver e elaborar problemas de multiplicação (por 2, 3, 4 e 5) com a ideia de adição de parcelas iguais por meio de estratégias e formas de registro pessoais, utilizando ou não suporte de imagens e/ou material manipulável"; e "Resolver e elaborar problemas envolvendo dobro, metade, triplo e terça parte, com o suporte de imagens ou material manipulável, utilizando estratégias pessoais." (MEC, 2017, p. 283). Ao concluir a aplicação do jogo, a docente analisou os dados sobre o desempenho dos estudantes e comprovou que as observações realizadas em sala de aula se confirmaram, pois os alunos não conseguiram acertar as questões relacionadas ao conteúdo de multiplicação e os que envolviam composição de troco.

Após conhecer um pouco do perfil dos estudantes, alguns questionamentos foram realizados com relação à questão da usabilidade, ou seja, o quanto é fácil utilizá-lo. O Gráfíco 2 ilustra as respostas obtidas para as questões pertencentes a três grandes grupos de itens que foram avaliados: 
a) estética - avaliar se a interface do jogo permite uma interação agradável e satisfatória para o usuário, neste caso 17 participantes acharam o design do jogo atraente;

b) aprendizibilidade - avaliar se o jogo pode ser usado por usuários especificados com objetivos específicos. Observa-se que, embora os alunos não tenham o costume de jogar, eles apontaram que foi fácil aprender o jogo e que não foram necessários muitos conhecimentos prévios para começar a jogar;

c) operacionalidade - o grau em que um jogo possui atributos que facilitam jogá-lo ou controlá-lo e se as regras estão claras. De acordo com o Gráfico e, é possível observar que a maioria das respostas obtidas são positivas ("Concordo fortemente") com relação a esse item avaliado.

d)

Gráfico 2 - Gráfico de avaliação da usabilidade do jogo

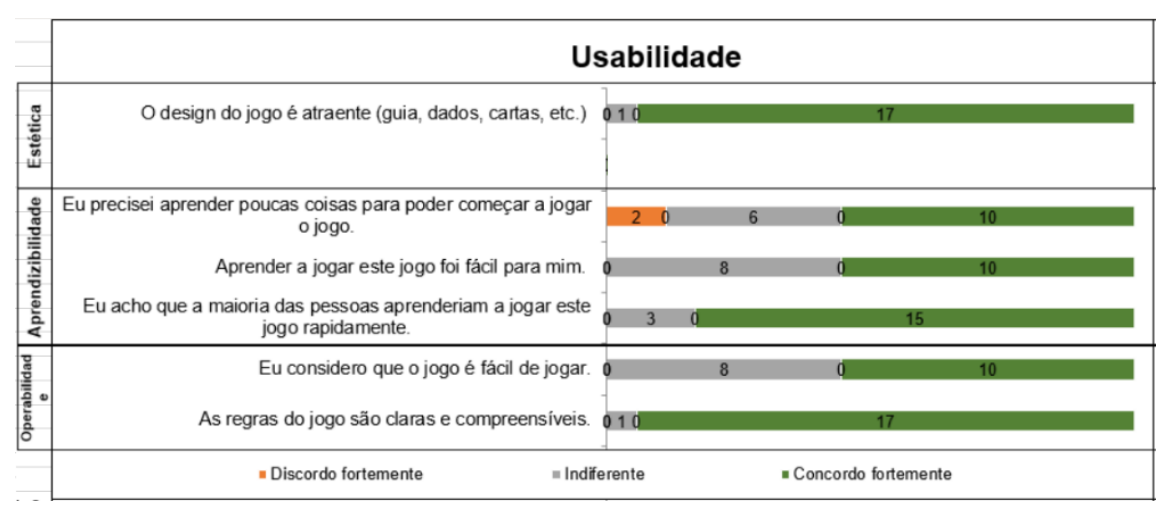

Fonte: Elaborado pelos autores, 2019.

Outro ponto que pode ser avaliado através do MEEGA+ diz respeito à experiência do jogador. As questões foram divididas em oito grupos: confiança - avaliar se os alunos são capazes de progredir no estudo do conteúdo educacional através de seu esforço e capacidade; desafio - analisar o quanto o jogo é suficientemente desafiador em relação ao nível de competência dos alunos; satisfação - verificar se os alunos sentem que o esforço dedicado resulta em aprendizado; interação social - determinar se o jogo promove a sensação de um ambiente compartilhado e estar conectado com outras pessoas em atividades de cooperação ou competição; diversão - considerar a sensação de prazer, felicidade, relaxamento e distração dos alunos; atenção focada - avaliando a atenção, concentração focada, absorção e dissociação temporal dos alunos; relevância - julgar se os alunos perceberam que a proposta educacional é consistente com seus objetivos profissionais ou acadêmicos futuros; percepção de aprendizagem - compreender as percepções do efeito geral do jogo sobre os alunos do curso (PETRI; WANGENHEIM; BORGATTO, 2018). Observa-se que no caso destes itens quase todos apresentaram avaliação positiva em sua maioria, conforme ilustram os Gráficos 3 e 4 . 
Gráfico 3 - Gráfico experiência ao jogar: desafio, satisfação, interação social e diversão

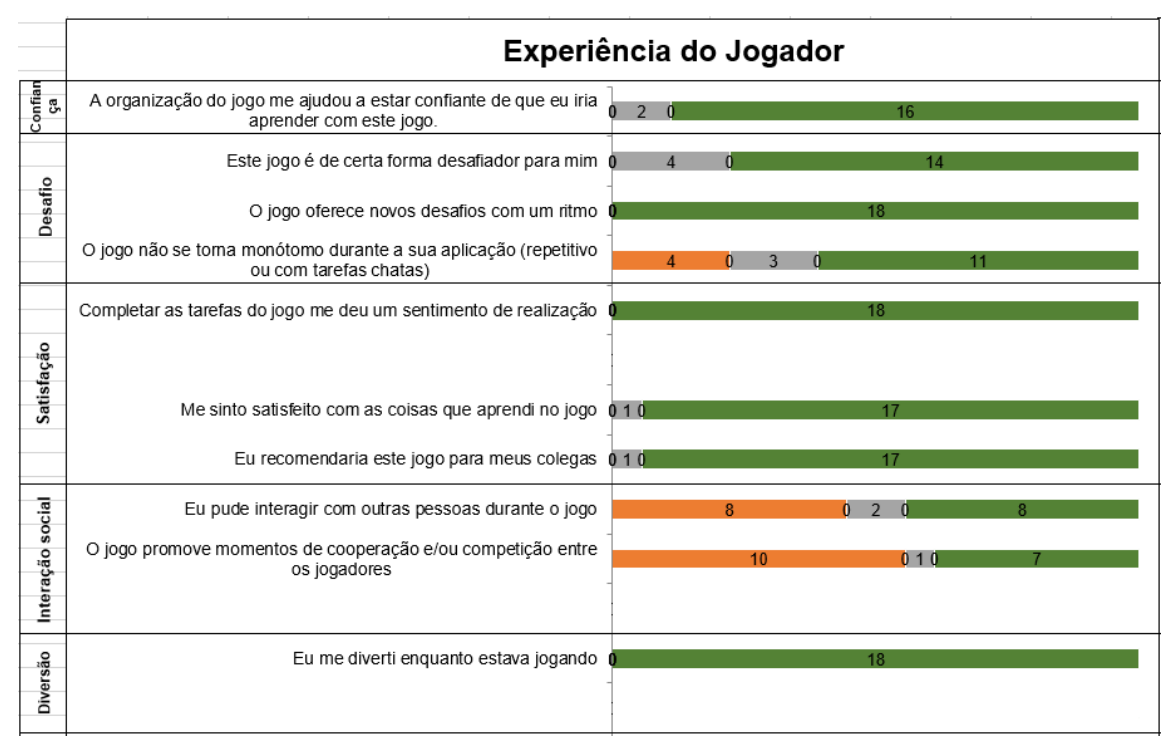

Fonte: Elaborado pelos autores, 2019.

Gráfico 4 - Gráfico experiência ao jogar: atenção focada, relevância e percepção da aprendizagem

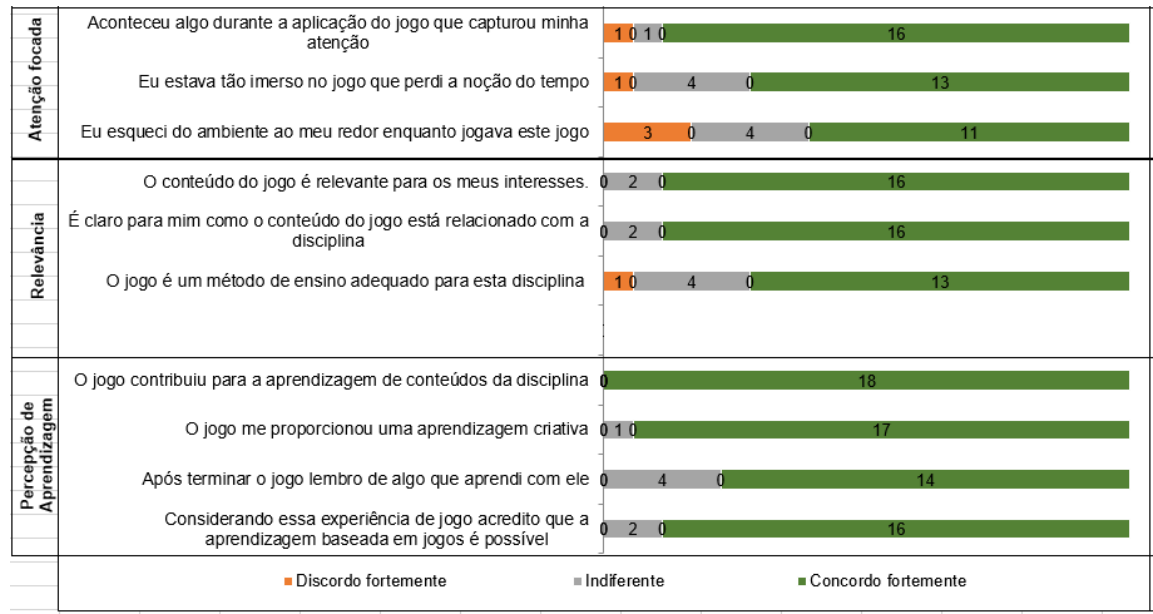

Fonte: Elaborado pelos autores, 2019.

Os estudantes apontaram como aspecto negativo do jogo a inexistências de interação social, demonstrando que os alunos gostariam que esse item fosse melhor explorado no jogo desenvolvido. Durante a aplicação, alguns alunos comentaram que seria interessante a integração do aplicativo com o Facebook, de modo que cada um pudesse saber a pontuação dos demais colegas da turma.

\section{Considerações finais}

O presente trabalho descreve o processo de criação, desenvolvimento e avaliação de um jogo sério para uso em sala de aula com o intuito de introduzir a educação financeira nos anos iniciais do Ensino Fundamental. Todo o projeto do jogo contou com a colaboração de estudantes que seriam o público alvo do jogo, bem como com a participação de docente vinculada ao tema, que elaborou as fases e níveis do jogo. 
O jogo foi avaliado usando o modelo MEEGA+, que permitiu analisá-lo em relação à experiência de jogo, à usabilidade e à aprendizagem. Os resultados positivos obtidos com essa aplicação motivaram novas experimentações com ele. Durante essa etapa de avaliação os participantes mencionaram diversas vezes que o aplicativo poderia ter "mais níveis", e que seria legal se ele "emitisse" sons conforme o progresso do usuário. Além disso, foi apontado que seria interessante que o aplicativo oportunizasse maior interação social. Na etapa de avaliação, os estudantes disseram que o jogo contribuiu para a aprendizagem de conteúdos da disciplina e que se divertiram enquanto jogavam. De maneira geral o feedback foi muito positivo, o que demonstra, em linhas gerais, que o objetivo do jogo foi alcançado com sucesso.

Destaca-se que o jogo possui como grande diferencial a possibilidade do docente utilizar o jogo como uma ferramenta que complementa a sua prática pedagógica. Com ela o docente pode verificar as principais dificuldades de aprendizagem dos estudantes, identificando em cada nível o número de acertos e erros. Com isso o docente pode mapear quais conteúdos podem ser reforçados em sala de aula ou, ainda, o uso de outras atividades pedagógicas que possam complementar as suas práticas.

\section{Referências}

ALVES, F. Gamification: como criar experiências de aprendizagem engajadoras. Um guia completo: do conceito à prática. 2. ed., São Paulo: DVS, 2014.

BATTISTELLA, P. E. ENgAGED: Um processo de desenvolvimento de jogos para ensino em computação. 2016. Tese (Doutorado em Ciência da Computação), PPGCC/Universidade Federal de Santa Catarina.

BRANCH, R. M. Instructional Design: The ADDIE Approach. New York: Springer, 2009.

BRASIL. Câmara dos Deputados. Projeto de Lei 7.318/2017. Brasília, 2017, 12p. Disponível em https://www.camara.leg.br/proposicoesWeb/fichadetramitacao?idProposicao=2128440. Acesso em: 10 set. 2019.

EID, M.; LAAMARTI, F.; SADDIK, A. An overview of serious games. International Journal of Computer Games Technology. n.11, jan., 2014.

Disponívelemhttps://dl.acm.org/doi/10.1155/2014/358152. Acesso em: 8 set., 2019.

ENEF.Estratégia Nacional de Educação Financeira. Plano Diretor da ENEF, Brasil, 2010.

Disponível em: <http://www.vidaedinheiro.gov.br/wp-content/uploads/2017/08/Plano-

Diretor-ENEF-Estrategia-Nacional-de-Educacao-Financeira.pdf $>$. Acesso em: 20 out. 2018.

GIRAFFA, L.; LIMA V.; e MARTINS, C. Gamificação e seus potenciais como estratégia pedagógica no Ensino Superior. Revista Novas Tecnologias na Educação (RENOTE), Porto Alegre, v. 16, n. 1, 10 p., 2018. Disponível em https://seer.ufrgs.br/renote/article/view/86005/49373. Acesso em: 21 jun., 2019.

KAPP, K. M. The gamification of learning and instruction: game-based methods and strategies for training and education. San Francisco: Pfeiffer, 2012. 
KIM, S.; SONG, K.; LOCKEE, B.; BURTON, J. Gamification in Learning and Education: enjoy learning like gaming. New York: Springer International Publishing, 2018.

MACEDO, L.; PETTY, A. L. S.; PASSOS, N. C. Os jogos e o Lúdico na Aprendizagem Escolar. Porto Alegre: Artmed, 2005.

MINISTÉRIO DA EDUCAÇÃO (MEC). Base Nacional Comum Curricular. 2017. Disponível em http://basenacionalcomum.mec.gov.br/wp-content/uploads/2018/02/bncc20dez-site.pdf. Acesso em: 15 jul. de 2018.

MORAIS, S. C. S; FALCÃO, T. P. Abordagem Participativa de Desenvolvimento de Jogos Digitais Educacionais no Contexto Escolar. Revista Brasileira de Informática na Educação, v. 27, n. 1, p. 132-153, 2019.

MORENO, C. Brasil cai em ranking mundial de educação em ciências, leitura e matemática, 2016. Disponível em https://g1.globo.com/educacao/noticia/brasil-cai-emranking-mundial-de-educacao-em-ciencias-leitura-e-matematica.ghtml. Acesso em: 15 Maio, 2019.

OCDE. Recomendação sobre os Princípios e as Boas Práticas de Educação e Conscientização Financeira. 2005. Disponível em https://www.oecd.org/daf/fin/financialeducation/[PT]\%20Recomenda\%C3\%A7\%C3\%A3o\%20Princ\%C3\%ADpios\%20de\%20Educ a\%C3\%A7\%C3\%A3o\%20Financeira\%202005\%20.pdf.Acesso em 11 Mar, 2020.

PRENSKY, M. Digital Game-Based Learning. ACM Computers in Entertainment, v. 1, v. 1, Oct., 2003. Disponível em:

https://dl.acm.org/doi/pdf/10.1145/950566.950596?download=true. Acesso em: 08 nov. 2018.

PETRI, G.;WANGENHEIM, C. G. v.; BORGATTO, A.F. Borgatto A.F. MEEGA+, Systematic Model to Evaluate Educational Games. In: Lee N. (eds) Encyclopedia of Computer Graphics and Games. Springer, 2018.

PETRI, G.; WANGENHEIM, C. G.; BORGATTO, A. F. MEEGA+: Um Modelo para a Avaliação de Jogos Educacionais para o ensino de Computação. Revista Brasileira de Informática na Educação, v. 27, n. 3, p. 52-81, 2019.

NETO, H. R. P.Gamificação: Engajando Pessoas de Maneira Lúdica. São Paulo: Fiap, 2015.

RIBEIRO, M., SANTOS, F. B. Brasil está entre os piores em ranking mundial de educação, 2016. Disponível em https://exame.abril.com.br/brasil/brasil-esta-entre-os-8piores-em-ciencias-em-ranking-de-educacao/. Acesso em: 15 Maio, 2019.

ROCHA, R. V. Metodologia iterativa e modelos integradores para desenvolvimento de jogos sérios de treinamento e avaliação de desempenho humano. Tese de Doutorado (Doutorado em Ciência da Computação), Universidade de São Carlos, 2014. Disponível em https://repositorio.ufscar.br/handle/ufscar/7594. Acesso em: 8 Mar., 2020.

ROCHA, R. V.; ZEM-LOPES, A. M.; PEDRO, L. Z.; BITTENCOURT, I. I.; ISOTANI, S. Metodologia de Desenvolvimento de Jogos Sérios: especificação de 
ferramentas de apoio open source. Revista Brasileira de Informática na Educação, v. 24, n. 3, p. 109-124, 2016.

ROGERS, Y.; SHARP, H.; PREECE, J. Design de Interação: além da interação humanocomputador. 3. ed. Porto Alegre: Bookman, 2013.

SILVA, P. P. Educação Financeira: uma proposta de cenário para investigação no ensino fundamental. Dissertação (Mestrado Profissional em Ensino de Matemática), São Paulo, 14 de fevereiro de 2020. Disponível em https://teses.usp.br/teses/disponiveis/45/45135/tde09032020-144721/publico/PEDRO.pdf. Acesso em: 18 Mar., 2020.

ZICHERMANN, G.; LINDER, J. The gamification revolution: how leaders leverage game mechanics to crush the competition. New York: McGraw-Hill, 2013.

Recebido em março de 2020.

Aprovado em maio de 2020. 